\title{
COMMENTARY
}

\section{The value of pupillary dilation in pre-emptive analgesia: is there more to this than meets the eye?}

Helen C Laycock ${ }^{*}$ and Carsten Bantel

See related research by Paulus et al., http://ccforum.com/content/17/4/R161

\begin{abstract}
The pupillary dilatation reflex may present an objective method of predicting whether sedated patients require additional analgesia for painful procedures. Behavioural pain assessment tools identify pain only once it has occurred and are unable to guide preemptive management. The pupillary dilatation reflex response to a tetanic stimulus has been utilised to assess analgesic requirements in patients under anaesthesia and for those with postoperative pain. This tool appears promising to assess pain in the critically ill; however, a number of questions remain unanswered regarding the influence of sedation on this response. These questions require further exploration before the pupillary dilatation reflex can be widely adopted into clinical practice.
\end{abstract}

In the current issue of Critical Care, Paulus and colleagues investigate whether the need for additional analgesia to prevent pain from endotracheal suctioning can be predicted by measuring the pupillary dilatation reflex (PDR) response to tetanic stimulation in deeply sedated patients [1].

This study touches on two important issues: objective pain assessments and pre-emptive analgesia. Pain in the critically unwell can lead to significant physiological and psychological consequences, and may affect patient outcome. Assessing pain in the critically ill is challenging. When patients are unable to self-report, assessment is based on behavioural and physical signs. Unfortunately physiological variables are not predictive of the presence

\footnotetext{
* Correspondence: helen.laycock@doctors.org.uk

Room G3.41, Anaesthetics, Pain Management and Intensive Care Section, Department of Surgery and Cancer, Imperial College London, Chelsea and
} Westminster Hospital Campus, 369 Fulham Road, London SW10 9NH, UK or absence of pain [2], and recommended behavioural tools (Critical Care Pain Observation Tool and Behavioural Pain Scale) [3] only identify patients who are experiencing pain.

Procedural pain is an integral component of the pain experience in critical care [4]. This pain is common and poorly managed $[5,6]$, explained in part by the inability of behavioural tools to predict those patients who require additional analgesia for painful procedures. Apart from chest drain removal, only low-grade evidence supports the use of pre-emptive analgesia for procedural pain [3] and over-administering opioids to patients is not without potential consequence [1]. Management at present is limited to either administering analgesia blindly before every procedure or taking a reactionary approach to treat pain after it has occurred. Both of these options are not ideal. The predictive utility of PDR to guide pre-emptive analgesia for painful procedures might be a possible solution to an important clinical question.

Physiologists have explored pupillary dilatation in response to noxious stimulus for over 300 years. Loewenfeld summarised this work and her own investigations in the late 1950s [7], and copious literature now exists exploring this phenomenon in adults and children under general anaesthesia [8], in awake volunteers [9], in organ donors [10] and in the postoperative period [11] as a means of assessing analgesic requirements. Larson and Sessler summarised in their editorial other influencing factors that clinicians need to consider when using PDR in pain assessment, including the effect of drugs and technical difficulties such as patient movement [12]. However, there are a number of questions that remain unanswered concerning the use of PDR in sedated patients, which should be considered. 
Paulus and colleagues are the first group to investigate PDR in response to tetanic stimuli in deeply sedated patients. The mechanism for this reflex differs between the awake and anaesthetised states. PDR is a supraspinal parasympathetic reflex in patients under general anaesthesia [13] but is sympathetically mediated in awake patients [10]. Which mechanism is present in sedated patients is not clear. Does the mechanism differ dependent on the depth of sedation and how does this affect PDR? Recently the PDR response to light has been shown to reduce with increased levels of sedation [14], and this needs to be explored in response to tetanic stimuli as well.

Furthermore, pupil size oscillates naturally (pupillary hippus) in the awake state. This is due to the spontaneous fluctuation between the tone and activity of the sympathetic and parasympathetic nervous systems [15]. Drowsiness can influence the frequency and amplitude of pupillary oscillations. Whether different depths of sedation make a similar contribution to pupil size and affect PDR remains elusive. Finally, the influence of different sedative pharmacological agents on the PDR response requires further investigation. Subgroup analysis by Paulus and colleagues did not demonstrate a difference between groups [1]. However, their small numbers warrant more research to exclude this potential influence.

The question of how to manage procedural pain in sedated patients is complex. The use of PDR to predict additional analgesic requirements for endotracheal suctioning, in deeply sedated patients, shows promise. The use of a non-invasive, innoculus stimulus in conjunction with PDR potentially provides an objective measure to guide pre-emptive analgesia. However, to make PDR a truly useful clinical tool, further research needs to address some of the questions raised above.

\section{Abbreviations}

PDR: Pupillary dilatation reflex

\section{Competing interests}

The authors declare that they have no competing interests.

\section{Acknowledgements}

$\mathrm{HCL}$ is funded by the National Institute of Health Research. CB is funded by the Higher Educational Funding Council for England and Chelsea and Westminster Hospital NHS Foundation Trust.

Published: 03 Sep 2013

\section{References}

1. Paulus J, Roquilly A, Beloeil H, Théraud J, Asehnoune K, Lejus C: Pupillary reflex measurement predicts insufficient analgesia before endotracheal suctioning in critically ill patients. Crit Care 2013, 17:R161.

2. Gelinas C, Arbour C: Behavioral and physiologic indicators during a nociceptive procedure in conscious and unconscious mechanically ventilated adults: similar or different? J Crit Care 2009, 24:628.e7-628.e17.

3. Barr J, Fraser GL, Puntillo K, Ely EW, Gelinas C, Dasta JF, Davidson JE, Devlin JW, Kress JP, Joffe AM, Coursin DB, Herr DL, Tung A, Robinson BR, Fontaine
DK, Ramsay MA, Riker RR, Sessler CN, Pun B, Skrobik Y, Jaeschke R, American College of Critical Care Medicine: Clinical practice guidelines for the management of pain, agitation, and delirium in adult patients in the intensive care unit. Crit Care Med 2013, 41:263-306.

4. Puntillo KA, White C, Morris AB, Perdue ST, Stanik-Hutt J, Thompson CL, Wild LR: Patients' perceptions and responses to procedural pain: results from Thunder Project II. Am J Crit Care 2001, 10:238-251.

5. Payen JF, Chanques G, Mantz J, Hercule C, Auriant I, Leguillou JL, Binhas M, Genty C, Rolland C, Bosson JL: Current practices in sedation and analgesia for mechanically ventilated critically ill patients: a prospective multicenter patient-based study. Anesthesio/ 2007, 106:687-695. Quiz 891-892.

6. Puntillo KA, Wild LR, Morris AB, Stanik-Hutt J, Thompson CL, White C: Practices and predictors of analgesic interventions for adults undergoing painful procedures. Am J Crit Care 2002, 11:415-429. quiz 430-431.

7. Loewenfeld IE: Mechanisms of reflex dilatation of the pupil; historical review and experimental analysis. Doc Ophthalmol Proc Ser 1958, 12:185-448.

8. Larson MD, Sessler DI, Washington DE, Merrifield BR, Hynson JA, McGuire J: Pupillary response to noxious stimulation during isoflurane and propofol anesthesia. Anesth Analg 1993, 76:1072-1078.

9. Chapman CR, Oka S, Bradshaw DH, Jacobson RC, Donaldson GW: Phasic pupil dilation response to noxious stimulation in normal volunteers: relationship to brain evoked potentials and pain report. Psychophysiol 1999, 36:44-52.

10. Yang LL, Niemann CU, Larson MD: Mechanism of pupillary reflex dilation in awake volunteers and in organ donors. Anesthesiol 2003, 99:1281-1286.

11. Aissou M, Snauwaert A, Dupuis C, Atchabahian A, Aubrun F, Beaussier M: Objective assessment of the immediate postoperative analgesia using pupillary reflex measurement: a prospective and observational study. Anesthesiol 2012, 116:1006-1012.

12. Larson MD, Sessler DI: Pupillometry to guide postoperative analgesia. Anesthesiol 2012, 116:980-982.

13. Larson MD, Tayefeh F, Sessler DI, Daniel M, Noorani M: Sympathetic nervous system does not mediate reflex pupillary dilation during desflurane anesthesia. Anesthesiol 1996, 85:748-754.

14. Rouche O, Wolak-Thierry A, Destoop Q, Milloncourt L, Floch T, Raclot P, Jolly $D$, Cousson J: Evaluation of the depth of sedation in an intensive care unit based on the photo motor reflex variations measured by video pupillometry. Ann Intensive Care 2013, 3:5.

15. Kawasaki A: Physiology, assessment, and disorders of the pupil. Curr Opin Ophthalmol 1999, 10:394-400.

\section{$10.1186 / \mathrm{cc} 12871$}

Cite this article as: Laycock and Bantel: The value of pupillary dilation in pre-emptive analgesia: is there more to this than meets the eye? Critical Care 2013, 17:178 